\title{
Editorial TS: 2nd international conference on structural adhesive bonding
}

\author{
Lucas F M da Silva ${ }^{1 *}$ and Robert D Adams ${ }^{2}$
}

\author{
* Correspondence: lucas@fe.up.pt \\ ${ }^{1}$ Departamento de Engenharia \\ Mecânica, Faculdade de Engenharia, \\ Universidade do Porto, Rua Dr. \\ Roberto Frias, 4200-465 Porto, \\ Portugal \\ Full list of author information is \\ available at the end of the article
}

This special issue of Applied Adhesion Science (AAS) contains selected papers presented at the 2nd International Conference on Structural Adhesive Bonding (AB 2013). AB 2013 was chaired by the two of us and was held in Porto, Portugal during July $4-5,2013$. The goal of the conference was to provide a unique opportunity to exchange information, present the latest results as well as to discuss issues relevant to structural adhesive bonding research today. Approximately 130 papers were presented by researchers from more than 20 countries.

In order to share the work presented at the conference, a selection of papers was made which resulted in the present Special Issue. The first paper by Quintino et al. is related to training and qualification of adhesive bonding personnel at the European level by the European Welding Federation (EWF). The courses are offered, namely European Adhesive Engineer, European Adhesive Specialist and European Adhesive Bonder. These courses are useful for companies to benefit from improved competitiveness in the global market place and from an increased likelihood of trouble-free production and service performance of their products. In the next paper, Paiva et al. study the importance of the surface treatment in the peeling strength of joints for the shoe industry. The authors considered the following materials: natural leather, thermoplastic rubber (TR), polyurethane (PU) and a polyurethane non structural adhesive solvent based. This work allows manufacturers of footwear to minimize the number of operations in the manufacture of shoes, while still being capable of satisfying the minimum requirements for the sector. In the third paper, Zhang et al. analysed the strength of adhesive joints of riser pipes in deep sea environment loadings such as external pressure, internal pressure, tension, torsion, bending loadings. The authors conclude that singular stress fields exist around the end of the interface. The riser pipe under external pressure, internal pressure and tension loading is more prone to break than under bending and torque loading. The last paper by Valoroso and De Barros is related to adhesive joint computations using cohesive zones. Numerical results are presented for a double cantilever beam geometry with varying thickness for which bilinear and exponential cohesive laws are considered. The authors conclude that the size of the process zone is found to be quite sensitive to the specimen characteristic size.

The preparation of this Special Issue has been an interesting experience for the guest editors. The review process gave a deeper insight into the various aspects of adhesive joints and the chance to discuss in detail the manuscripts directly with the authors. We would like to thank the authors for their patience with the process and the 
reviewers for providing critical evaluations of these manuscripts. Finally, we especially thank Dr Silvio de Barros, Editor-in-Chief of AAS who made this Special Issue possible.

\section{Author details}

'Departamento de Engenharia Mecânica, Faculdade de Engenharia, Universidade do Porto, Rua Dr. Roberto Frias, 4200-465 Porto, Portugal. ${ }^{2}$ Department of Engineering Science, University of Oxford, Parks Road, Oxford, UK.

Received: 22 December 2013 Accepted: 22 December 2013

Published: 17 January 2014

doi:10.1186/2196-4351-2-9

Cite this article as: da Silva and Adams: Editorial TS: 2nd international conference on structural adhesive bonding. Applied Adhesion Science 2014 2:9.

Submit your manuscript to a SpringerOpen ${ }^{\circ}$ journal and benefit from:

- Convenient online submission

- Rigorous peer review

- Immediate publication on acceptance

- Open access: articles freely available online

- High visibility within the field

- Retaining the copyright to your article

Submit your next manuscript at $>$ springeropen.com 